\title{
In situ probing of surface hydrides on hydrogenated amorphous silicon using attenuated total reflection infrared spectroscopy
}

\author{
Citation for published version (APA): \\ Kessels, W. M. M., Marra, D. C., Sanden, van de, M. C. M., \& Aydil, E. S. (2002). In situ probing of surface \\ hydrides on hydrogenated amorphous silicon using attenuated total reflection infrared spectroscopy. Journal of \\ Vacuum Science and Technology A: Vacuum, Surfaces, and Films, 20(3), 781-789. \\ https://doi.org/10.1116/1.1469012
}

DOI:

10.1116/1.1469012

Document status and date:

Published: 01/01/2002

\section{Document Version:}

Publisher's PDF, also known as Version of Record (includes final page, issue and volume numbers)

\section{Please check the document version of this publication:}

- A submitted manuscript is the version of the article upon submission and before peer-review. There can be important differences between the submitted version and the official published version of record. People interested in the research are advised to contact the author for the final version of the publication, or visit the DOI to the publisher's website.

- The final author version and the galley proof are versions of the publication after peer review.

- The final published version features the final layout of the paper including the volume, issue and page numbers.

Link to publication

\footnotetext{
General rights

- You may freely distribute the URL identifying the publication in the public portal. follow below link for the End User Agreement:

www.tue.nl/taverne

\section{Take down policy}

If you believe that this document breaches copyright please contact us at:

openaccess@tue.nl

providing details and we will investigate your claim.
}

Copyright and moral rights for the publications made accessible in the public portal are retained by the authors and/or other copyright owners and it is a condition of accessing publications that users recognise and abide by the legal requirements associated with these rights.

- Users may download and print one copy of any publication from the public portal for the purpose of private study or research.

- You may not further distribute the material or use it for any profit-making activity or commercial gain

If the publication is distributed under the terms of Article $25 \mathrm{fa}$ of the Dutch Copyright Act, indicated by the "Taverne" license above, please 


\title{
In situ probing of surface hydrides on hydrogenated amorphous silicon using attenuated total reflection infrared spectroscopy
}

\author{
W. M. M. Kessels ${ }^{a}$ \\ Department of Applied Physics, Eindhoven University of Technology, P.O. Box 513, 5600 MB Eindhoven, \\ The Netherlands \\ Denise C. Marra \\ Department of Chemical Engineering, University of California Santa Barbara, Santa Barbara, \\ California 93106-5080 \\ M. C. M. van de Sanden \\ Department of Applied Physics, Eindhoven University of Technology, P.O. Box 513, 5600 MB Eindhoven, \\ The Netherlands
}

Eray S. Aydil ${ }^{\text {) }}$

Department of Chemical Engineering, University of California Santa Barbara, Santa Barbara, California 93106-5080

(Received 12 April 2000; accepted 15 February 2002)

\begin{abstract}
An in situ method based on attenuated total reflection Fourier transform infrared spectroscopy (ATR-FTIR) is presented for detecting surface silicon hydrides on plasma deposited hydrogenated amorphous silicon $(a-\mathrm{Si}: \mathrm{H})$ films and for determining their surface concentrations. Surface silicon hydrides are desorbed by exposing the $a-\mathrm{Si}: \mathrm{H}$ films to low energy ions from a low density Ar plasma and by comparing the infrared spectrum before and after this low energy ion bombardment, the absorptions by surface hydrides can sensitively be separated from absorptions by bulk hydrides incorporated into the film. An experimental comparison with other methods that utilize isotope exchange of the surface hydrogen with deuterium showed good agreement and the advantages and disadvantages of the different methods are discussed. Furthermore, the determination of the composition of the surface hydrogen bondings on the basis of the literature data on hydrogenated crystalline silicon surfaces is presented, and quantification of the hydrogen surface coverage is discussed. (C) 2002 American Vacuum Society. [DOI: 10.1116/1.1469012]
\end{abstract}

\section{INTRODUCTION}

Investigation of plasma-surface interactions in plasma deposition of materials and the effect of these interactions on the deposited film properties requires knowledge of both the plasma and surface composition. While there have been many studies on the identity and concentration of gas phase species in $\mathrm{SiH}_{4}$ containing discharges used for deposition of hydrogenated amorphous silicon $(a-\mathrm{Si}: \mathrm{H})$, studies on the composition of the surface during deposition are scarce. For $a-\mathrm{Si}: \mathrm{H}$, the hydrogen coverage of the surface is expected to influence the film quality through its effect on the interaction mechanisms of radicals impinging on the surface with the film. Surface reactions can also affect ${ }^{1,2}$ the incorporation of dangling bonds, leading to electronic defects, and the incorporation of hydrogen which influences the opto-electronic properties of the material such as the absorption coefficient and the optical band gap. ${ }^{3,4}$ Furthermore, the interaction of atomic hydrogen from the plasma with the film affects the film morphology, 3,4 and it is believed that hydrogen in the

\footnotetext{
a)Electronic mail: w.m.m.kessels@tue.nl

b) Author to whom correspondence should be addressed; electronic mail: aydil@engineering.ucsb.edu
}

film plays an important role in the photoinduced degradation of the electronic properties, the so-called Staebler-Wronski effect. $^{4-6}$

Information on silicon surface hydrides $\left(\mathrm{SiH}_{x}, x \leqslant 3\right)$ can be obtained through surface sensitive infrared absorption spectroscopy (in all its diversities), preferentially by in situ and real-time monitoring of the film growth. The study of the surface hydrides is made difficult by the fact that the weak absorptions due to surface $\mathrm{Si}-\mathrm{H}$ stretching modes cannot easily be discerned from the strong absorption by $\mathrm{SiH}_{x}$ bonds in the $a-\mathrm{Si}: \mathrm{H}$ bulk film. This problem can be partially solved by studying the absorption during the initial stages of film growth for ultrathin $a-\mathrm{Si}: \mathrm{H}$ films. ${ }^{7-11}$ These experiments have indicated that mainly higher hydrides $\left(\mathrm{SiH}_{2}\right.$ and $\left.\mathrm{SiH}_{3}\right)$ are present during the initial film growth, but one cannot distinguish whether these higher hydrides are present at the substrate-film interface and/or at the film-vacuum interface (the surface) for thicker films. In fact, these experiments do not reveal information about the surface composition and coverage under steady-state film growth conditions. In an attempt to resolve this information, Miyoshi et al. deposited $a-\mathrm{Si}: \mathrm{H}$ on as grown $a-\mathrm{Si}: \mathrm{H}$ films and analyzed the infrared spectra with respect to the spectrum of the as grown films. ${ }^{12}$ However, in spectra collected this way possible changes in the bulk $\mathrm{SiH}_{x}$ bonds cannot be distinguished from changes in 
TABLE I. Experimental conditions for deposition of $a$-Si:H, ion bombardment assisted desorption of the surface hydrides by an Ar plasma, and the isotope exchange experiments with an $\mathrm{Ar}-\mathrm{D}_{2}$ plasma.

\begin{tabular}{lccc}
\hline \hline & Deposition & $\begin{array}{c}\text { Ion } \\
\text { bombardment }\end{array}$ & $\begin{array}{c}\text { Isotope } \\
\text { exchange }\end{array}$ \\
\hline Ar flow $(\mathrm{sccm})$ & 50 & 50 & 50 \\
Ar/SiH $(1 \%)$ flow (sccm) & 50 & $\ldots$ & $\ldots$ \\
$\mathrm{D}_{2}$ flow (sccm) & $\ldots$ & $\ldots$ & 5 \\
Power (W) & 50 & 100 & 50 \\
Pressure (mTorr) & 40 & 20 & 40 \\
\hline \hline
\end{tabular}

the newly deposited film and interactions of the plasma with the underlying film are obscured. This problem can be avoided by using methods that rely on isotope substitution. For example, Toyoshima et al. were able to detect the surface hydrides by depositing $a$-Si:D from a $\mathrm{SiD}_{4}$ plasma on top of an $a$-Si:H film. ${ }^{13,14}$ In such an experiment, the removal of the surface hydrides initially present on the $a-\mathrm{Si}: \mathrm{H}$ surface is not obscured by $\operatorname{SiD}_{x}$ absorptions in the newly deposited $a$-Si:D film. A similar technique relies on the exposure of $a-\mathrm{Si}: \mathrm{H}$ films to atomic deuterium while monitoring the decrease in $\mathrm{SiH}_{x}$ absorption due to the replacement of surface hydrides with their deuterated counterparts. ${ }^{11,12,15}$ This method also reveals the interactions of atomic deuterium (hydrogen) with $a-\mathrm{Si}: \mathrm{H}$ films, which are not limited only to hydrogen substitution at the surface. ${ }^{16}$ A method recently applied to study the surface hydrides on amorphous and nanocrystalline silicon films ${ }^{17}$ is the removal of the surface hydrides by low-energy $(\sim 20 \mathrm{eV})$ ion bombardment using a low ion density Ar plasma. The absorption by the hydrides before and after this Ar plasma was measured by attenuated total reflection Fourier transform infrared spectroscopy (ATR-FTIR). In this article, this technique is described in greater detail and the influence of the Ar plasma on the film is determined. Furthermore, a comparison between this technique and the above-mentioned methods using isotope substitution is given. The validity of the different techniques in terms of probing the surface hydrides is discussed along with their applicability and accuracy.

\section{EXPERIMENTAL SETUP}

The experiments were conducted in an inductively coupled plasma reactor at $13.56 \mathrm{MHz},{ }^{17}$ and the conditions for deposition, ion bombardment assisted desorption of the surface hydrides, and the isotope exchange experiments with $\mathrm{D}_{2}$ are listed in Table I. For all conditions, the reflected power was less than $5 \%$ and the base pressure in the reactor was $10^{-7}$ Torr.

The ATR-FTIR setup is described in detail in Ref. 17. Briefly, GaAs (100) ATR crystals were used to extend the spectral range of the study down to $800 \mathrm{~cm}^{-1}$. The number of total reflections at each side is 35 , leading to a sensitivity in reflectance $R$ of $\Delta R / R \approx 1.4 \times 10^{-5}$ per reflection. The resolution of the spectrometer was set at $4 \mathrm{~cm}^{-1}$ and spectra were collected in the range of $750-4000 \mathrm{~cm}^{-1}$. However, this study focuses on the regions containing the stretching a)

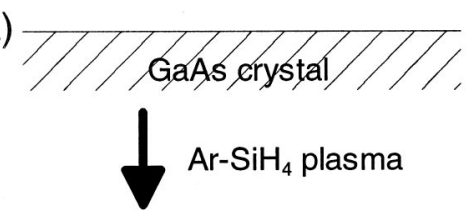

b)
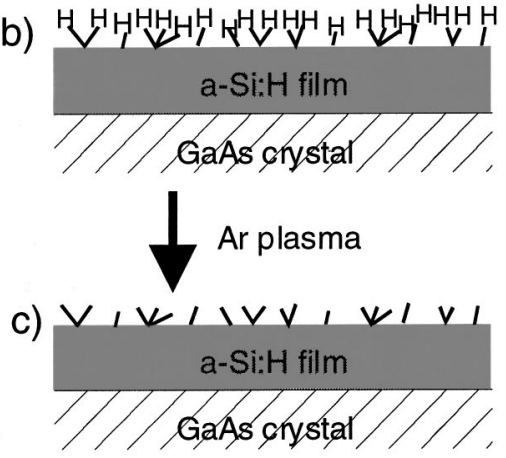

FIG. 1. Schematic representation of the method used for probing surface and bulk hydrides in $a$-Si:H by ATR-FTIR. Hydrogen in both the bulk and on the interfaces is probed by taking a spectrum (b) during or after deposition with respect to a spectrum (a) of a clean crystal. Surface hydrides are probed by taking a spectrum (c) after ion bombardment, using an Ar plasma, with respect to a spectrum (b) of the film after deposition. In the text, spectrum (b) is referred to as the reference spectrum.

vibrations of the hydrides ("deuterides"). This is around $2100 \mathrm{~cm}^{-1}$ for hydrogen and $1500 \mathrm{~cm}^{-1}$ for deuterium. No polarization dependent studies have been performed. The absorptions are, however, measured with equal sensitivity in both polarizations because the electric field strength is about equal for the three components of the electric field at the $a-\mathrm{Si}: \mathrm{H}$ surface for the angle of incidence used in this study. ${ }^{18,19}$

\section{PROBING OF SURFACE HYDRIDES BY ION BOMBARDMENT ASSISTED DESORPTION}

\section{A. Procedure and identification of surface hydrides}

Approximately $200 \AA$ thick $a$-Si:H films were deposited on ATR crystals and infrared spectra of the films were monitored in real time. At $200 \AA$ the ratio of the absorption by bulk hydrides at $\sim 2000 \mathrm{~cm}^{-1}$ (attributed to isolated $\mathrm{SiH}$ ) and $\sim 2100 \mathrm{~cm}^{-1}$ (attributed to $\mathrm{SiH}_{2}$ and clustered $\mathrm{SiH}$ at internal surfaces) had already reached a steady state. Following the deposition, a reference spectrum was collected by averaging 1000 scans, which results in a total collection time of nearly $7 \mathrm{~min}$. Subsequently, an Ar plasma was ignited for $2 \mathrm{~s}$, using the pulse mode of a programmable rf power supply, and a spectrum with 1000 scans was collected with respect to the reference spectrum that was taken immediately after deposition. The $2 \mathrm{~s}$ long Ar plasma exposures were usually repeated up to a total exposure time of $10 \mathrm{~s}$, collecting an infrared spectrum each time with respect to the reference spectrum of the as deposited film. This procedure is illustrated schematically in Fig. 1 and as will be shown below the spectrum taken after $10 \mathrm{~s}$ of Ar plasma exposure gives a very good indication of the hydrides initially present on the surface. 


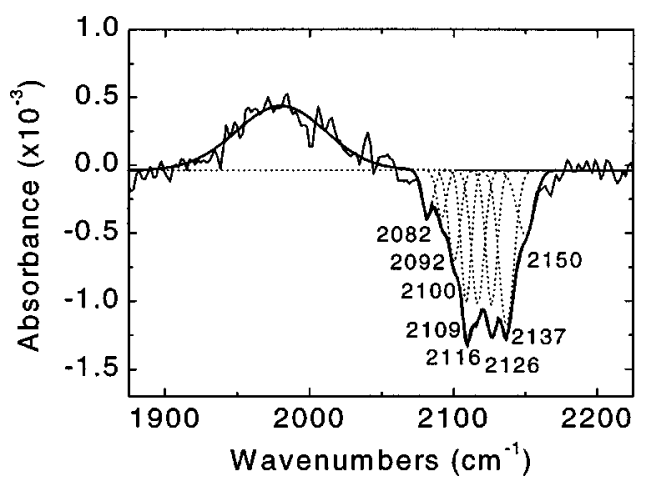

FIG. 2. Infrared spectrum of the surface hydrides $\mathrm{SiH}_{x}\left(2075-2150 \mathrm{~cm}^{-1}\right)$ on an $a$-Si:H film deposited at $230^{\circ} \mathrm{C}$. The absorbance band is deconvoluted into several narrow Gaussian peaks (positions are indicated) corresponding to different configurations of $\mathrm{Si}-\mathrm{H}$ bonds on the surface as described in the text. The broad peak centered at $\sim 1970 \mathrm{~cm}^{-1}$ corresponds to Ar plasma induced changes in the bulk hydrides.

Figure 2 shows the spectrum of the surface silicon hydrides for a film deposited at $230{ }^{\circ} \mathrm{C}$ obtained using the method described above with $10 \mathrm{~s}$ Ar plasma exposure. Note that this spectrum is collected with respect to the reference spectrum of the as deposited film and that the spectrum only shows the changes that have taken place due to the $\mathrm{Ar}$ plasma exposure. The absorption is expressed in absorbance $\left[=-{ }^{10} \log \left(I / I_{\text {ref }}\right)\right.$, where $I / I_{\text {ref }}$ is the ratio of the infrared radiation intensity after and before ion bombardment, respectively]. Thus negative values of absorbance correspond to absorbing species removed from the film while positive values of absorbance correspond to newly generated absorptions. The absorption band between $\sim 2070$ and $\sim 2150 \mathrm{~cm}^{-1}$ is therefore due to surface hydrides removed by ion bombardment. The peak centered at $\sim 1970 \mathrm{~cm}^{-1}$ is related to Ar plasma induced changes in the bulk $a-\mathrm{Si}: \mathrm{H}$, which appear at lower wave numbers and which are much broader. Fortunately, these absorptions do not interfere with the higher frequency surface hydride modes. The absorption between 2070 and $2150 \mathrm{~cm}^{-1}$ shows some features and it can be deconvoluted into several narrow Gaussians with a full width half maximum in the range of $6-14 \mathrm{~cm}^{-1}$, although sometimes on the level of noise, the features are expected to correspond to different configurations of hydrogen present at the surface and are therefore narrow. This has been supported by the fact that the features were consistently present, for all sputtering times and also under different plasma conditions and substrate temperatures. In fact, the exact deconvolution procedure involved an iterative approach in which multiple spectra were fitted using nonlinear least-squares optimization with different numbers of peaks. The total number of peaks and their positions were decided based on the need to include them to reproduce the features consistently observed in different spectra. Although some influence of noise cannot be excluded, it is believed that by far most of the features are real and that the deconvolution is appropriate. This is also corroborated by the agreement between the peak positions (within the resolution) and those obtained by numerous infrared absorption spectroscopy experiments on hydrogenated crystalline silicon $(c-\mathrm{Si})$ surfaces of various crystal orientations and surface reconstructions. ${ }^{20-30}$ These studies are also used for assigning the different absorption peaks due to the different silicon hydride configurations present on the surface. Some of the assignments are still under debate, but most literature agrees on the following division. Absorption peaks at wave numbers between $\sim 2070$ and $\sim 2100 \mathrm{~cm}^{-1}$ correspond to silicon monohydrides $(\mathrm{SiH})$ on the surface, between $\sim 2100$ and $\sim 2130 \mathrm{~cm}^{-1}$ to silicon dihydrides $\left(\mathrm{SiH}_{2}\right)$, and between $\sim 2130$ and $\sim 2150 \mathrm{~cm}^{-1}$ to silicon trihydrides $\left(\mathrm{SiH}_{3}\right)$. A complication is the observation of $\mathrm{SiH}_{2}$ vibrations at $2091 \mathrm{~cm}^{-1}$ (symmetric stretch) and $2097 \mathrm{~cm}^{-1}$ (isolated) on the $\mathrm{Si}(100)-(3 \times 1)$ surface $^{24}$ and the observation of $\mathrm{SiH}_{3}$ vibrations at $2126 \mathrm{~cm}^{-1}$ (asymmetric stretch) on the $\operatorname{Si}(111)-(7 \times 7)$ surface. ${ }^{25}$ Yet these are exceptions to the aforementioned division, which is expected to give a good approximate indication of the surface composition. For $a-\mathrm{Si}: \mathrm{H}$ some controversy about the assignment of surface $\mathrm{Si}-\mathrm{H}$ stretching modes still exists in the literature, but the majority of the studies are in approximate agreement with the above-mentioned assignments. ${ }^{11,12,14,15}$ Some minor discrepancies exist for the assignment of absorptions around $2100 \mathrm{~cm}^{-1}, 11,14$ but cases in which absorptions by $\mathrm{SiH}$ are assumed to have higher wave numbers than absorptions by $\mathrm{SiH}_{2}$ (at, respectively, 2115 and $2091 \mathrm{~cm}^{-1}$ ) 31 may be erroneous on the basis of the data available for hydrogenated $c$-Si. ${ }^{20-30}$ The composition of the $a-\mathrm{Si}: \mathrm{H}$ surface in terms of mono-, di-, and trihydrides is obtained by adding the total integrated absorbances peaking in the three aforementioned regions. This lumping of absorptions makes the determination of the surface composition less sensitive to the details of the deconvolution procedure. In terms of absorbance, the dihydride mode is dominant on the $a-\mathrm{Si}: \mathrm{H}$ surface at $230^{\circ} \mathrm{C}$ as can be seen in Fig. 2. ${ }^{17,32}$ Expressed in absorbance, the distribution of hydrogen in the different hydrides is approximately $13 \%$ in $\mathrm{SiH}, 51 \%$ in $\mathrm{SiH}_{2}$, and $36 \%$ in $\mathrm{SiH}_{3}$. Whether the surface contains mainly $\mathrm{SiH}_{2}$ at $230{ }^{\circ} \mathrm{C}$ depends on the relative oscillator strengths for the different stretching modes at the surface. This information is not available for $\mathrm{SiH}_{x}$ bondings at the surface. The oscillator strengths for bulk hydrides are available, but not completely unambiguous. For the ratio of oscillator strengths of the bulk hydrogen stretching modes at $\sim 2000$ and $\sim 2100 \mathrm{~cm}^{-1}$, values ranging between 1 and 3 have been proposed. ${ }^{33-36}$ On the other hand, for hydrogen stretching modes in silane gases, it is found that the oscillator strength per $\mathrm{Si}-\mathrm{H}$ bond is roughly the same for all the silanes. ${ }^{37}$ Thus the distribution of the $\mathrm{SiH}_{x}$ absorbance may be presumed to be representative and a good approximation of the surface composition, as also indicated by the results in Ref. 32. For the $a-\mathrm{Si}: \mathrm{H}$ surface at $230{ }^{\circ} \mathrm{C}$, this would mean that $26 \%$ of the surface $\mathrm{Si}$ atoms are bonded to one hydrogen atom $(\mathrm{SiH}), 50 \%$ to two hydrogen atoms $\left(\mathrm{SiH}_{2}\right)$, and $24 \%$ to three hydrogen atoms $\left(\mathrm{SiH}_{3}\right)$. In this way, the final composition of the surface can be determined reproducibly within 5\% accuracy as calculated from the standard deviation of experiments carried out at least in triplicates. 


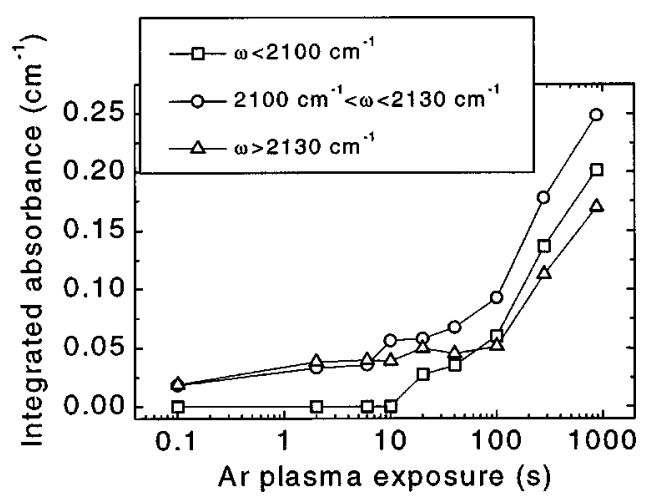

FIG. 3. Influence of the Ar plasma exposure time on the total integrated absorbance in the region $2075-2150 \mathrm{~cm}^{-1}$. For exposure times $\leqslant 10 \mathrm{~s}$ the regions of the spectrum below $2100 \mathrm{~cm}^{-1}$, between 2100 and $2130 \mathrm{~cm}^{-1}$, and above $2130 \mathrm{~cm}^{-1}$ correspond to surface mono-, di-, and trihydrides, respectively. For longer times broad absorptions appear below $2100 \mathrm{~cm}^{-1}$ and around $2100 \mathrm{~cm}^{-1}$, corresponding to isolated $\mathrm{SiH}$, and $\mathrm{SiH}_{2}$ and clustered $\mathrm{SiH}$ in bulk $a$-Si:H, respectively. This indicates that subsurface or bulk hydrogen is removed as well after $\sim 10 \mathrm{~s}$ of Ar plasma exposure. The film used for generating this figure was deposited at $160{ }^{\circ} \mathrm{C}$.

\section{B. Effect of Ar plasma exposure time}

The influence of the plasma exposure time on the spectra and the selection of an exposure time of $10 \mathrm{~s}$ for the determination of the surface composition are addressed next. Ideally the films should be exposed to the Ar plasma only for the time necessary to remove all the hydrides present on the surface. ${ }^{38}$ This time is, however, not easily defined and we have explored the optimum Ar plasma exposure time by studying the changes in the infrared spectrum of the surface as a function of the exposure time. Figure 3 shows the integrated absorbances as a function of Ar plasma exposure time for the three wave number regions mentioned above for a film deposited at $160{ }^{\circ} \mathrm{C}$. During the first $10 \mathrm{~s}$ of Ar plasma exposure only the surface hydrides (only $\mathrm{SiH}_{2}$ and $\mathrm{SiH}_{3}$ are present at $\left.160{ }^{\circ} \mathrm{C}\right)^{32}$ are removed. This is evidenced by slight increases in their absorbances with increasing exposure time while their relative distribution remains roughly constant. However, when the film is exposed to the Ar plasma longer than $10 \mathrm{~s}$, a rather abrupt increase in absorbance is observed along with an increase in contribution from wave numbers $<2100 \mathrm{~cm}^{-1}$. The latter is due to the appearance of a broad absorption at these lower wave numbers and this corresponds to removal of bulk-like $\mathrm{SiH}_{x}$ bonds. This indicates that at these longer times, not only the surface hydrides are desorbed but that $\mathrm{H}$ is removed from the subsurface or from the bulk of the film as well. In fact, bulk $\mathrm{SiH}_{x}$ bonds have absorptions centered at $\sim 2015$ and $\sim 2100 \mathrm{~cm}^{-1}$ for films deposited at $160^{\circ} \mathrm{C}$ and the fact that after $16 \mathrm{~min}$ of Ar plasma exposure the $\mathrm{SiH}$ absorption is still not centered at $\sim 2015$ $\mathrm{cm}^{-1}$ but at slightly higher wave numbers indicates that still no real bulk $a$-Si:H has been sputtered but only the subsurface layer. It can be concluded that at up to $\sim 10 \mathrm{~s}$ of $\mathrm{Ar}$ plasma exposure only the surface hydrides are removed. This conclusion is corroborated by spectroscopic ellipsometry measurements where for Ar plasma exposure times up to 10 $\mathrm{s}$ no changes in the film thickness have been observed. ${ }^{39}$
Figure 3 shows that even for shorter Ar plasma exposure times a good indication of the surface composition can be obtained, but at $\sim 10 \mathrm{~s}$ the best signal-to-noise ratio is achieved because the absorbance corresponding to the removed surface hydrides is at a maximum. The integrated absorbance at this time will correspond approximately to the total amount of hydrogen present on the surface, i.e., the hydrogen surface coverage. Yet an accurate determination of this coverage will suffer from the difficulty in exactly determining the integrated absorbance corresponding to surface hydrides. This will be discussed in Sec. V. Finally, it should be noted that the time of Ar plasma exposure necessary to remove only the surface hydrides depends strongly on the properties of the plasma used for ion bombardment assisted desorption. Under the presented conditions, the ion energy and flux are approximately $20 \mathrm{eV}$ and $2 \times 10^{15} \mathrm{~cm}^{-2} \mathrm{~s}^{-1}$, respectively. ${ }^{32}$ Thus a $10 \mathrm{~s}$ Ar plasma exposure corresponds to an ion dose of $2 \times 10^{16} \mathrm{~cm}^{-2}$, which is in the expected order of magnitude to remove approximately 1 monolayer of adsorbates.

\section{COMPARISON WITH METHODS USING ISOTOPE SUBSTITUTION}

\section{A. Deposition of a-Si:H on a-Si:D}

In this section the method of probing the surface hydrides by Ar ion bombardment as described in Sec. III is compared with other methods presented in the literature. First a comparison is made with the method used by Toyoshima et al. ${ }^{14}$ and Toyoshima ${ }^{40}$ who obtained the surface composition by depositing $a-\mathrm{Si}: \mathrm{H}$ on an $a$-Si:D film while monitoring the surface deuterides removed from the initial surface. In the present study, $\mathrm{SiD}_{4}$ was not available to exactly duplicate this procedure, and $a-\mathrm{Si}: \mathrm{D}$ films were created by exposing $a-\mathrm{Si}: \mathrm{H}$ films to an $\mathrm{Ar}-\mathrm{D}_{2}$ plasma for $1 \mathrm{~min}$. This leads to an exchange of the hydrogen in a large fraction of the film and certainly in the topmost regions as evidenced by infrared spectra taken in real time. Subsequently, $a-\mathrm{Si}: \mathrm{H}$ was deposited onto this film and information on the surface composition was obtained. The surface spectra cannot directly be compared with those of Toyoshima ${ }^{40}$ because the $\mathrm{Ar}-\mathrm{D}_{2}$ plasma treatment can also induce other changes in the bulk and at the surface, such as deuterium insertion in $\mathrm{Si}-\mathrm{Si}$ bonds and $a$-Si:H etching. ${ }^{16}$ For the present purpose, which is to compare different methods for obtaining the surface composition, the effect of these changes is made irrelevant. This is done by comparing the surface spectrum obtained by the above mentioned method with a spectrum obtained by ion assisted desorption of deuterium from an $a$-Si:D film prepared by $\mathrm{Ar}-\mathrm{D}_{2}$ plasma treatment as well. Information about the assignments of the absorption peaks in the stretching region has been obtained from data available for deuterated $c$-Si surfaces. ${ }^{21-23}$

The spectrum for the surface silicon deuterides, obtained by exposing an $a$-Si:D film deposited at $230{ }^{\circ} \mathrm{C}$ to an $\mathrm{Ar}$ plasma for $10 \mathrm{~s}$, is shown in Fig. 4(a). The spectra obtained by depositing $a-\mathrm{Si}: \mathrm{H}$ on top of the $a-\mathrm{Si}: \mathrm{D}$ are shown in the 


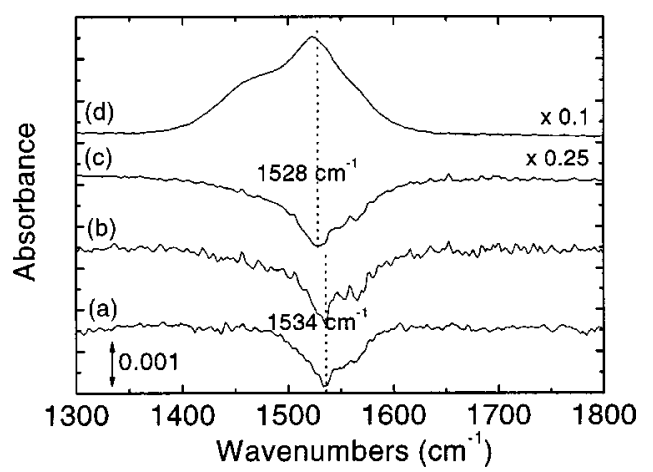

FIG. 4. Comparison between the infrared surface spectrum of an $a$-Si:D film deposited at $230{ }^{\circ} \mathrm{C}$ obtained: (a) by Ar ion bombardment, and by depositing $a-\mathrm{Si}: \mathrm{H}$ on top of the $a-\mathrm{Si}: \mathrm{D}$ film (b) for $4 \mathrm{~s}$ and (c) for $28 \mathrm{~s}$. An infrared spectrum (d) of bulk $a-\mathrm{Si}: \mathrm{D}$ is given for comparison.

same figure: Figures 4(b) and 4(c) correspond to $a-\mathrm{Si}: \mathrm{H}$ deposition times of 4 and $28 \mathrm{~s}$, respectively. Comparison of the spectra shows that Fig. 4(b), recorded after $4 \mathrm{~s}$ of $a-\mathrm{Si}: \mathrm{H}$ deposition on $a$-Si:D, resembles Fig. 4(a) both in absolute magnitude of absorbance and in peak positions. On the other hand, Fig. 4(c), recorded after $28 \mathrm{~s}$ of $a-\mathrm{Si}: \mathrm{H}$ deposition on $a$-Si:D, shows a much higher magnitude of absorbance and, more importantly, peak positions different from those in Figs. 4(a) and 4(b). In Fig. 4(c), the dominant absorption is centered at $1528 \mathrm{~cm}^{-1}$ instead of $1534 \mathrm{~cm}^{-1}$, as is the case for both Figs. 4(a) and 4(b). Furthermore, the shoulder at higher wave numbers is less pronounced in Fig. 4(c). From a comparison with a spectrum of bulk $a$-Si:D [Fig. 4(d)], which has broad absorption peaks centered at 1475 and 1525 $\mathrm{cm}^{-1}$, it can be concluded that during the $28 \mathrm{~s}$ of $a-\mathrm{Si}: \mathrm{H}$ deposition in Fig. 4(c) the underlying $a$-Si:D bulk is influenced by the $\mathrm{SiH}_{4}$ plasma. The fact that the absorption peaks are not yet centered at the positions of the bulk deuterides indicates that only the probably less dense region close to the surface is influenced. Apparently, depositing $a-\mathrm{Si}: \mathrm{H}$ on top of an $a$-Si:D film eventually not only removes the surface deuterides but also induces changes in the bulk $a$-Si:D. This can occur by hydrogen diffusion or by penetration of the film by radicals or ions from the plasma. In fact, this experiment shows that the reactions that lead to deposition and hydrogen incorporation take place not only on the surface but most likely in a thin reaction zone that includes subsurface layers. These changes are not observable for short deposition times when the $\mathrm{SiH}_{4}$ plasma has only had time to affect the surface. Indications for bulk modification already appear after 7 $\mathrm{s}$. This illustrates that caution is required when this method is applied: when the film is exposed too long to the $\mathrm{SiH}_{4}$ plasma ( $\geqslant \sim 7 \mathrm{~s}$ for the present experimental conditions and consequently more sensitive to time than $\mathrm{Ar}$ ion bombardment), not only are the deuterides on the surface removed but also the underlying film is changed. This can complicate the determination of the surface composition when this method is used.

From Figs. 4(a) and 4(b) the surface composition of the $a$-Si:D film at $230^{\circ} \mathrm{C}$ can be determined by deconvoluting the $\mathrm{SiD}_{x}$ absorption band with absorption peaks centered at

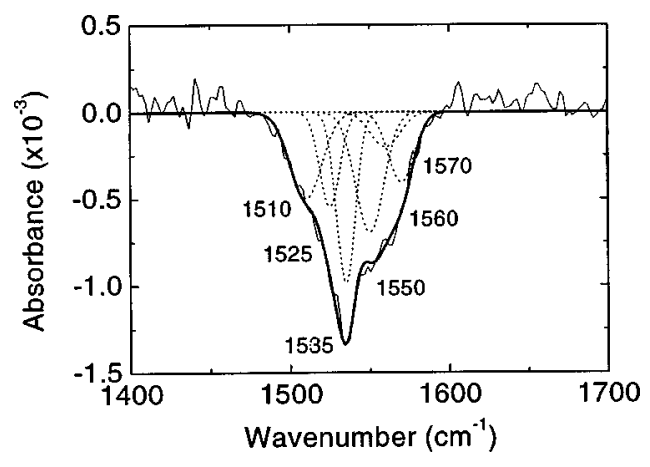

FIG. 5. Spectrum (a) from Fig. 4, obtained by Ar ion bombardment of an $a$-Si:D film deposited at $230^{\circ} \mathrm{C}$, deconvoluted into several narrow Gaussian peaks (positions are indicated). These peaks correspond to different configurations of $\mathrm{Si}-\mathrm{D}$ bonds on the surface as described in the text.

1510, 1525, 1535, and $1550-1570 \mathrm{~cm}^{-1}$ (See Fig. 5). These absorptions are attributed to $\mathrm{SiD}, \mathrm{SiD}_{2} / \mathrm{SiD}_{3}, \mathrm{SiD}_{2}$, and $\mathrm{SiD}_{3}$ stretching modes, respectively. ${ }^{21-23}$ As both $\mathrm{SiD}_{2}$ and $\mathrm{SiD}_{3}$ contribute to the absorption at $1525 \mathrm{~cm}^{-1}$, the absorbance at this position is divided among $\mathrm{SiD}_{2}$ and $\mathrm{SiD}_{3}$ on the basis of the ratio of their absorbances at 1535 and 1550 $1570 \mathrm{~cm}^{-1}$, respectively. For the surface composition of the $a$-Si:D films at $230{ }^{\circ} \mathrm{C}$ this means that, in terms of absorbance, $\sim 15 \%$ of the surface deuterium is bonded as $\mathrm{SiD}$, $\sim 35 \%$ as $\mathrm{SiD}_{2}$, and $\sim 50 \%$ as $\mathrm{SiD}_{3}$. Compared to the $a$-Si:H surface at $230{ }^{\circ} \mathrm{C}$, the $a$-Si:D surface contains relatively more $\mathrm{SiD}_{3}$ at the expense of $\mathrm{SiD}_{2}$. This can possibly be attributed to the preparation method of the $a$-Si:D film (Ar- $\mathrm{D}_{2}$ exposure of $a-\mathrm{Si}: \mathrm{H}$ ) also causing insertion of deuterium in $\mathrm{Si}-\mathrm{Si}$ bonds at the surface.

We note that, if one assumes that spectrum (c) shows a pure "surface spectrum" with no contribution of the bulk, one would most probably draw roughly the same conclusion about the dominant bonding configuration of the surface deuterides, yet on a wrong basis. This can lead to erroneous interpretations, especially in attempts to quantify the surface composition. In conclusion, the method of depositing $a-\mathrm{Si}: \mathrm{H}$ on $a$-Si:D (or vice versa) also requires a careful examination of the influence of deposition time (more so than for the ion bombardment assisted desorption method) as changes in the bulk are easily induced.

\section{B. D/H exchange by $\mathrm{Ar}-\mathrm{D}_{2}$ plasma exposure}

Another method of probing the surface hydrides on $a-\mathrm{Si}: \mathrm{H}$ is by replacing them with atomic deuterium generated from a $\mathrm{D}_{2}$ plasma. ${ }^{11,12,15}$ We investigated this method by exposing an $a$-Si:H film deposited at $230{ }^{\circ} \mathrm{C}$ to an $\mathrm{Ar}-\mathrm{D}_{2}$ plasma for different amounts of time. In Fig. 6, the spectra of this film taken after $0.2 \mathrm{~s}$ [Fig. 6(b)] and after $7 \mathrm{~s}$ [Fig. 6(c)] of $\mathrm{Ar}-\mathrm{D}_{2}$ plasma exposure are given. It is expected that for a properly chosen exposure time, atomic deuterium will replace the hydrogen atoms on the surface, and that the corresponding decrease in absorbance due to the removed hydrides yields an indication of the composition of the surface. On the other hand, the increased absorbance due to the newly created surface deuterides does not give a good indication of 


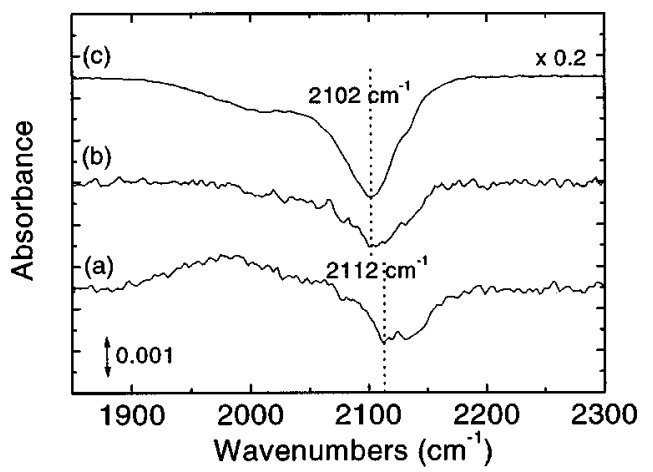

FIG. 6. Comparison between infrared surface spectrum of an $a$-Si:H film deposited at $230{ }^{\circ} \mathrm{C}$ obtained (a) by $\mathrm{Ar}$ ion bombardment and by exposing the $a-\mathrm{Si}: \mathrm{H}$ to an $\mathrm{Ar}-\mathrm{D}_{2}$ plasma (b) for $0.2 \mathrm{~s}$ and (c) for $7 \mathrm{~s}$.

the surface composition because atomic deuterium can also induce other changes at the surface. ${ }^{16}$ This has no implications for the absorbance corresponding to the disappearing hydrides as this region of the spectrum shows only what has been removed from the surface. However, the fact that this technique does not work out properly can be seen in Fig. 6 . A comparison between the spectrum taken after $0.2 \mathrm{~s} \mathrm{Ar}-\mathrm{D}_{2}$ plasma [Fig. 6(b)] and that taken after $10 \mathrm{~s}$ Ar plasma exposure [Fig. 6(a)] shows a discrepancy in the positions of the (dominant) absorbances. The main peak in Fig. 6(a) is positioned at $2112 \mathrm{~cm}^{-1}$, while the main peak after deuterium substitution is positioned at $2102 \mathrm{~cm}^{-1}$. This shift to lower wave numbers is also observed for longer exposure times [e.g., in Fig. 6(c)] and implies that hydrogen in the bulk is affected by the $\mathrm{Ar}-\mathrm{D}_{2}$ plasma exposure. Deuterium substitution is apparently very fast compared to the removal of the surface hydrides by ion bombardment or by deposition. The fact that the total absorbance of Fig. 6(b) is roughly of the same order of magnitude as for Fig. 6(a) implies that modifications in the bulk occur before the hydrogen on the surface is completely substituted by deuterium. This fast bulk change is possibly due to fast diffusion of deuterium in $a-\mathrm{Si}: \mathrm{H}$ and/or to deuterium ions in the $\mathrm{Ar}-\mathrm{D}_{2}$ plasma, which can easily penetrate the film. Because of this simultaneous modification of the bulk, spectra showing only the surface hydrides cannot be obtained by an $\mathrm{Ar}-\mathrm{D}_{2}$ plasma, not even when the exposure time is decreased. An interaction by deuterium ions can be circumvented by using atomic deuterium, e.g., created on a hot filament. However, thus far mainly plasmas have been used to create atomic deuterium for probing the surface hydrides. ${ }^{11,12,15}$

\section{DISCUSSION}

From the results, it can be concluded that absorptions by surface hydrides and by bulk hydrides can be distinguished by comparing infrared spectra before and after Ar ion assisted desorption of surface hydrides and that this method gives an accurate and unambiguous representation of the surface composition. Furthermore, this method is easier to apply than the techniques that utilize isotope substitution. The surface deuterium removal by depositing $a-\mathrm{Si}: \mathrm{H}$ on top of an
$a-\mathrm{Si}: \mathrm{D}$ film is also a viable method for determining the surface hydride composition and results obtained using this method are in good agreement with the ion bombardment assisted desorption method. However, deuterium removal by depositing $a-\mathrm{Si}: \mathrm{H}$ on $a-\mathrm{Si}: \mathrm{D}$ is more sensitive to exposure time due to fast deuterium substitution in the bulk. Probing the surface composition by substituting hydrogen with deuterium using an $\mathrm{Ar}-\mathrm{D}_{2}$ plasma is complicated for the same reason. Moreover, bulk hydrogen substitution can occur on even shorter time scales, even before all surface hydrides have been replaced, rendering this method unfeasible. Furthermore, using an Ar plasma to probe the surface hydrides has a practical advantage of eliminating the need for $\mathrm{D}_{2}$ or, very expensive, $\mathrm{SiD}_{4}$. Moreover, the ion assisted desorption technique can also be used in a broad range of (plasma) deposition and surface modification processes, even in cases where isotope substitution experiments are unfeasible, e.g., in the study of fluorine surface termination. A disadvantage common to all three techniques is that no real time information on the surface composition during film growth is obtained. In all three cases the film deposition has to be stopped to take a reference infrared spectrum. Complications can arise especially when thermal hydrogen desorption from the surface takes place. The time between deposition and probing of the surface can, however, be shortened by using a technique with enhanced sensitivity like attenuated total reflection infrared spectroscopy.

Concerning the determination of the surface composition by Ar ion bombardment, the best accuracy has been obtained after an Ar plasma exposure of $10 \mathrm{~s}$. This corresponds roughly to the time necessary to completely remove the hydrides from the surface (see Fig. 3). Although easier than the methods using isotope substitution, it is still difficult to decide accurately on the time necessary to remove exactly all surface hydrogen. This complicates the determination of the hydrogen surface coverage from the infrared absorbance. Another problem in calculating the surface coverage is the lack of knowledge about oscillator strengths or proportionality constants of the different hydride configurations that relate the hydrogen areal density to the infrared absorbance. Two approaches have been used in the literature for estimating the $a$-Si:H hydrogen surface coverage.

In the first approach, the proportionality constants for hydrogen in the bulk of $a-\mathrm{Si}: \mathrm{H}$ determined by, for example, Langford et $a l^{33}$ have been used. This procedure has been applied by Katiyar et al., ${ }^{9}$ Toyoshima et al., ${ }^{14}$ and von Keudell and Abelson ${ }^{41}$ who all used data on the bulk stretching mode at $2100 \mathrm{~cm}^{-1}$. The number of hydrogen bonds is related to the integrated absorption coefficient [i.e., $\int(\alpha / \omega) d \omega$, where $\alpha$ is the absorption coefficient and $\omega$ is the frequency] by the proportionality constant $A$. $A$ is theoretically defined as ${ }^{33,37}$

$$
A=\frac{c n \mu \omega}{2 \pi^{2} e_{S}^{* 2}},
$$

where $c$ is the speed of light, $n$ is the refractive index, $\mu$ is the reduced mass, and $e_{S}^{*}$, is the effective charge of the 
dipole in the solid. Values for $A$ between $1.4 \times 10^{20}$ and 2.2 $\times 10^{20} \mathrm{~cm}^{-2}$ have been reported in the literature for the 2100 $\mathrm{cm}^{-1}$ bulk absorption peak in $a-\mathrm{Si}: \mathrm{H}$ and from these values, an effective charge of $\sim 0.3-0.4$ has been calculated. ${ }^{33,36} \mathrm{It}$ is claimed $^{36,37}$ that the effective charge of the dipole in the solid $e_{S}^{*}$ is related to the effective charge $e_{G}^{*}$ of the same oscillator in a gas molecule by a local field correction. This local field correction, which is still under discussion, ${ }^{36,37}$ causes the effective charge of a dipole in a solid to be larger than the corresponding one in a gaseous molecule. ${ }^{37,42}$ When the above $A$ values for bulk hydrogen are used to calculate the hydrogen surface coverage, it is assumed that the required local field correction and therefore also the effective charge for the surface hydrides are identical to those for the bulk hydrides. This assumption is not trivial because there is a large shift (up to $\sim 80 \mathrm{~cm}^{-1}$ ) in absorption frequencies for bulk hydrogen as compared to surface hydrogen and this frequency shift depends, among other factors, on the effective charge of the dipole. ${ }^{30}$ Another aspect is that the refractive index in Eq. (1) is lower in the surface region than in the bulk. Assuming 50\% voids and using Bruggeman's effective medium theory, ${ }^{43}$ a $40 \%$ lower refractive index is estimated on the surface. Neglecting these aspects and applying the proportionality constants for hydrogen in bulk $a-\mathrm{Si}: \mathrm{H}$ to convert the surface infrared absorbance data in Fig. 2 to surface hydrogen coverage yields a surface hydrogen areal density of $(3.0-4.6) \times 10^{14} \mathrm{~cm}^{-2}$.

In the second approach, surface infrared absorbance data on hydrogenated $c$-Si surfaces have been used to obtain the hydrogen surface coverage on $a$-Si:H surfaces. ${ }^{17}$ Jakob et al. have reported an integrated absorbance of 2.27 $\times 10^{-3} \mathrm{~cm}^{-1}$ for the stretching mode at $2086 \mathrm{~cm}^{-1}$ due to 1 monolayer of hydrogen on a ideally terminated $\mathrm{Si}(111)$ surface $\left(7.83 \times 10^{14} \mathrm{~cm}^{-2} \mathrm{H}\right.$ atoms $) .{ }^{30}$ When this absorbance is expressed as the integrated absorption coefficient $\left[\int(\alpha / \omega) d \omega\right]$ and linked to the monolayer coverage, the corresponding proportionality constant $A$ for a $\mathrm{Si}(111)$ surface can be calculated to be $3.13 \times 10^{20} \mathrm{~cm}^{-2}$. Using this proportionality constant yields an amount of hydrogen removed from the surface of the film in Fig. 2 of $6.7 \times 10^{14} \mathrm{~cm}^{-2}$. This coverage is larger than the one found when applying the values proposed for bulk hydrogen. An important difference in this respect is that the effective charge of the $\mathrm{SiH}$ oscillators on the $\mathrm{Si}(111)$ surface as calculated by Jakob et al. is $0.120 \pm 0.005{ }^{30}$ This is much smaller than the values of the effective charge proposed for bulk hydrogen.

This second approach, using the literature data on a hydrogenated $\mathrm{Si}(111)$ surface, seems to be more appropriate. It gives a higher hydrogen coverage and it would therefore correspond better to the fact that the hydrogen surface coverage is expected to be close to unity for $a-\mathrm{Si}: \mathrm{H}$ (see below). ${ }^{44,45}$ The approach is also more straightforward in the sense that no important assumptions need to be made about the local field correction, because basically the local field is expected to be similar for both the $a-\mathrm{Si}: \mathrm{H}$ and the $\mathrm{Si}(111)$ surface. There is however a complication. The $\mathrm{SiH}$ oscillators on a $\mathrm{Si}(111)$ surface are aligned, and therefore the electric field experienced by one oscillator is screened by the dipole fields of all the other oscillators. This leads to a screened effective charge by a macroscopic screening factor $\varepsilon_{\infty}:{ }^{19}$

$$
e^{*}{ }_{\text {screened }}=e^{*}{ }_{\text {unscreened }} / \varepsilon_{\infty} \text {. }
$$

The macroscopic screening factor for the fully hydrogenated $\mathrm{Si}(111)$ surface calculated by Jakob et al. is $2.0 \pm 0.4,{ }^{30}$ while for the $\mathrm{Si}(100)-(2 \times 1)$ surface, Chabal has estimated a macroscopic screening factor $\varepsilon_{\infty}$ of $\sim 1.4 .{ }^{19}$ The amount of screening is actually expected to be approximately equal for both the $\mathrm{Si}(111)$ and $\mathrm{Si}(100)-(2 \times 1)$ surface and the rather large uncertainties in these values should be taken into account in this respect. ${ }^{46}$ No information is available about screening on an $a$-Si:H surface, but taking the above considerations into account, the screening for the $a$-Si:H surface might be somewhat lower than for $c$-Si surfaces due to the amorphous nature of the $a$-Si:H. Large differences are not expected because no shift in the frequencies of the different $\mathrm{SiH}_{x}$ stretching absorptions has been observed (within the resolution) compared to $c$-Si surfaces.

From the above discussion, it is clear that calculating the amount of hydrogen on the $a$-Si:H surface is a complicated matter. Different approaches have been applied in the literature each with their own uncertainties. Although we have a preference for the second approach, not enough information is available to decide on which approach is the most appropriate for the $a$-Si:H surface. An additional difficulty is that the number of $\mathrm{Si}$ surface sites is unknown for the $a-\mathrm{Si}: \mathrm{H}$ films. This inhibits an exact calculation of the hydrogen surface coverage of $a-\mathrm{Si}: \mathrm{H}$, which is considered to be a very relevant parameter in $a$-Si:H film growth. ${ }^{1,2}$ Assuming the $a$-Si:H surface to be $\mathrm{Si}(100)-(1 \times 1)$ like [i.e., a $\mathrm{Si}$ surface site density equal to that of $\mathrm{Si}(100)$ with also on average 2 hydrogen atoms per surface $\mathrm{Si}$ atom] a hydrogen surface coverage of an $\sim 0.2-0.3$ equivalent monolayer is obtained when applying the bulk proportionality constants and $\sim 0.5$ monolayer when using the data on hydrogenated $\mathrm{Si}(111)$. These values of the coverage are not close to unity for both cases as is expected for $a-\mathrm{Si}: \mathrm{H},{ }^{44,45}$ but this can be due to a lower $\mathrm{Si}$ surface site density of the $a$-Si:H compared to $c-\mathrm{Si}$ surfaces (especially here, where we used a very diluted $\mathrm{Ar}-\mathrm{SiH}_{4}$ mixture to deposit the $\left.a-\mathrm{Si}: \mathrm{H}\right)$. Interestingly, calculations of the hydrogen surface density on $a$-Si:H films "grown" by molecular dynamics simulations using $\mathrm{SiH}_{3}$ as the sole precursor ${ }^{45}$ have revealed a hydrogen surface areal density of $5-7 \times 10^{14} \mathrm{~cm}^{-2}$ for a substrate temperature of $230^{\circ} \mathrm{C}$. This is in good agreement with the experimental value when applying the second approach with the data for hydrogenated $c$-Si surfaces. Moreover, the simulations revealed a relatively low surface dangling bond density while the simulated and experimental surface composition in terms of hydrides showed very good agreement. ${ }^{45}$ This suggests that the second approach is most appropriate for calculating areal densities of hydrogen on $a-\mathrm{Si}: \mathrm{H}$ surfaces. Furthermore, the rather low experimental and simulated hydrogen surface coverage can also indicate a considerable degree of surface 
reconstruction; for example, the hydrogen coverage of the reconstructed $\mathrm{Si}(111)-(7 \times 7)$ surface is only 3 $\times 10^{14} \mathrm{~cm}^{-2}$.

Finally, it should be mentioned that the surface is not well defined for $a$-Si:H and it should be taken into account that the surface site density and thus the hydrogen coverage increase with increasing surface roughness. The surface hydrogen areal density can therefore depend on, e.g., the substrate temperature and film thickness. ${ }^{32}$ The main conclusion of this discussion is therefore also that the calculation of surface coverage of $a$-Si:H from infrared absorption data is not as straightforward as sometimes presented. ${ }^{9,41}$ This also complicates the determination of the surface coverage of hydrogen as a function of substrate temperature in order to draw conclusions about the surface dangling bond density as done in Ref. 14.

\section{CONCLUSIONS}

A recently developed method ${ }^{17}$ to determine the surface hydride composition on plasma deposited $a$-Si:H by means of in situ attenuated total reflection infrared spectroscopy has been studied in detail. In this method, absorptions due to surface hydrides are distinguished from absorptions by hydrides in the bulk $a$-Si:H by removing the hydrogen at the surface with an Ar plasma and by comparing the infrared spectra of the film taken before and after ion bombardment. Herein, the influence of Ar plasma exposure has been investigated and the time necessary to remove only surface hydrides has been established. The determination of the surface composition in terms of mono-, di-, and trihydrides on the basis of data available for hydrogenated $c$-Si surfaces is addressed and the quantification of the hydrogen surface coverage by using data from ideally hydrogen terminated $c$-Si surfaces and from bulk $a-\mathrm{Si}: \mathrm{H}$ has been discussed.

Furthermore, the method of Ar ion bombardment has been compared with other techniques using isotope substitution. A good agreement has been found with the method in which $a-\mathrm{Si}: \mathrm{H}$ is deposited on $a-\mathrm{Si}: \mathrm{D}$ to reveal the surface deuterides. However, it is shown that the Ar ion bombardment method is preferable for the experimental conditions used, particularly in comparison with isotope substitution by means of an $\mathrm{Ar}-\mathrm{D}_{2}$ plasma. In this case, fast substitution of bulk hydrogen has been observed even before the substitution of surface hydrogen was completed. Another advantage of the Ar ion bombardment method is that it is applicable in a much wider range of (plasma) deposition and surface modification processes.

\section{ACKNOWLEDGMENTS}

This article is based upon work supported under a National Science Foundation Graduate Fellowship. This work was supported by the NSF/DOE Partnership of Plasma Science and Engineering Award (Grant No. DMR 97-13280). In situ ATR-FTIR was developed with support from the National Science Foundation Young Investigator Award (Grant No. ECS 94-57758). W.K. acknowledges the Netherlands Organization for Scientific Research (NWO) and the Center for Plasma Physics and Radiation Technology (CPS) for their financial support. The authors thank Professor P. Jakob, Professor D.C. Schram, Professor D. Maroudas, and S. Ramalingam for fruitful discussions.

${ }^{1}$ A. Matsuda, Plasma Phys. Controlled Fusion 39, A431 (1997).
${ }^{2}$ M. C. M. van de Sanden, W. M. M. Kessels, R. J. Severens, and

${ }^{2}$ M. C. M. van de Sanden, W. M. M. Kessels, R. J. Severens, and D. C. Schram, Plasma Phys. Controlled Fusion 41, A365 (1999).

${ }^{3}$ W. Luft and Y. S. Tsuo, Hydrogenated Amorphous Silicon Alloy Deposition Processes (Dekker, New York, 1993).

${ }^{4}$ R. A. Street, Hydrogenated Amorphous Silicon (Cambridge University Press, New York, 1991).

${ }^{5}$ M. Stutzman, W. B. Jackson, and C. C. Tsai, Phys. Rev. B 32, 23 (1985). ${ }^{6}$ H. M. Branz, Phys. Rev. B 59, 5498 (1999).

${ }^{7}$ Y. Toyoshima, K. Arai, A. Matsuda, and K. Tanaka, Appl. Phys. Lett. 56, 1540 (1990).

${ }^{8}$ N. Blayo and B. Drevillon, J. Non-Cryst. Solids 137-138, 771 (1991).

${ }^{9}$ M. Katiyar, Y. H. Yang, and J. R. Abelson, J. Appl. Phys. 77, 6247 (1995).

${ }^{10}$ J. Knobloch and P. Hess, Appl. Phys. Lett. 69, 4041 (1996).

${ }^{11}$ S. Miyazaki, H. Shin, Y. Miyoshi, and M. Hirose, Jpn. J. Appl. Phys., Part 1 34, 787 (1995).

${ }^{12}$ Y. Miyoshi, Y. Yoshida, S. Miyazaki, and M. Hirose, J. Non-Cryst. Solids 198-200, 1029 (1996).

${ }^{13}$ Y. Toyoshima, K. Arai, A. Matsuda, and K. Tanaka, Appl. Phys. Lett. 57, 1028 (1990).

${ }^{14}$ Y. Toyoshima, K. Arai, A. Matsuda, and K. Tanaka, J. Non-Cryst. Solids 137-138, 765 (1991)

${ }^{15}$ R. Nozawa, H. Takeda, M. Ito, M. Hori, and T. Goto, J. Appl. Phys. 85, 1172 (1999).

${ }^{16}$ C.-M. Chiang, S. M. Gates, S. S. Lee, M. Kong, and S. F. Bent, J. Phys. Chem. B 101, 9537 (1997).

${ }^{17}$ D. C. Marra, E. A. Edelberg, R. L. Naone, and E. S. Aydil, J. Vac. Sci. Technol. A 16, 3199 (1998).

${ }^{18}$ N. J. Harrick, Internal Reflection Spectroscopy (Wiley, New York 1967).

${ }^{19}$ Y. J. Chabal, Surf. Sci. Rep. 8, 211 (1988).

${ }^{20}$ Y. J. Chabal, G. S. Higashi, and S. B. Christman, Phys. Rev. B 28, 4472 (1983).

${ }^{21}$ Y. J. Chabal and K. Raghavachari, Phys. Rev. Lett. 53, 282 (1984).

${ }^{22}$ Y. J. Chabal and K. Raghavachari, Phys. Rev. Lett. 54, 1055 (1985).

${ }^{23}$ V. A. Burrows, Y. J. Chabal, G. S. Higashi, K. Raghavachari, and S. B. Christman, Appl. Phys. Lett. 53, 998 (1988).

${ }^{24}$ Y. J. Chabal, G. S. Higashi, K. Raghavachari, and V. A. Burrows, J. Vac. Sci. Technol. A 7, 2104 (1989).

${ }^{25}$ K. J. Uram and U. Jansson, J. Vac. Sci. Technol. B 7, 1176 (1989).

${ }^{26}$ U. Jansson and K. J. Uram, J. Chem. Phys. 91, 7978 (1989).

${ }^{27}$ K. J. Uram and U. Jansson, Surf. Sci. 249, 105 (1991).

${ }^{28}$ Y. J. Chabal, in Internal Reflection Spectroscopy: Theory and Application, edited by F. M. Mirabella, Jr. (Dekker, New York, 1993), p. 191.

${ }^{29}$ P. Jakob, P. Dumas, and Y. J. Chabal, Appl. Phys. Lett. 59, 2968 (1991).

${ }^{30}$ P. Jakob, Y. J. Chabal, and K. Raghavachari, Chem. Phys. Lett. 187, 325 (1991).

${ }^{31}$ J. A. Glass Jr., E. A. Wovchko, and J. T. Gates, Jr., Surf. Sci. 348, 325 (1996).

${ }^{32}$ D. C. Marra, W. M. M. Kessels, M. C. M. van de Sanden, K. Kashefizadeh, and E. S. Aydil (unpublished).

${ }^{33}$ A. A. Langford, M. L. Fleet, B. P. Nelson, W. A. Lanford, and N. Maley, Phys. Rev. B 45, 13367 (1992).

${ }^{34}$ C. Manfredotti, F. Fizzotti, M. Boero, P. Pastorino, P. Polesello, and E. Vittone, Phys. Rev. B 50, 18046 (1994).

${ }^{35}$ W. M. M. Kessels, M. C. M. van de Sanden, R. J. Severens, L. J. van IJzendoorn, and D. C. Schram, Mater. Res. Soc. Symp. Proc. 507, 529 (1998).

${ }^{36}$ W. Beyer and M. S. Abo Ghazala, Mater. Res. Soc. Symp. Proc. 507, 601 (1998).

${ }^{37}$ M. H. Brodsky, M. Cardona, and J. J. Cuomo, Phys. Rev. B 16, 3556 (1977).

${ }^{38} \mathrm{The} a-\mathrm{Si}: \mathrm{H}$ surface is not very well defined and it is not excluded that $\mathrm{Si}$ atoms bonded to the surface hydrogen are desorbed. This has no direct implications for the interpretation of the data.

${ }^{39}$ D. C. Marra, E. A. Edelberg, R. L. Naone, and E. S. Aydil, Appl. Surf. 
Sci. 133, 148 (1998).

${ }^{40}$ Y. Toyoshima, Thin Solid Films 234, 367 (1993).

${ }^{41}$ A. von Keudell and J. R. Abelson, Phys. Rev. B 59, 5791 (1999).

${ }^{42}$ L. Genzel and T. P. Martin, Surf. Sci. 34, 33 (1973).

${ }^{43}$ D. A. G. Bruggeman, Ann. Phys. (Leipzig) 24, 636 (1935).
${ }^{44}$ S. Yamasaki, T. Umeda, J. Isoya, and K. Tanaka, J. Non-Cryst. Solids 227-230, 83 (1998).

${ }^{45}$ S. Ramalingam, S. Sriraman, E. S. Aydil, and D. Maroudas, Appl. Phys. Lett. 78, 2685 (2001)

${ }^{46} \mathrm{P}$. Jakob (private communication). 